\title{
ANÁLISE DE SITUAÇÕES DE PACIENTES AGRESSIVOS EM UNIDADE DE TERAPIA INTENSIVA
}

Ângela Gonçalves da Silva', Thaíse Liara da Silva², Mariluci Alves Maftum³, Marcio Roberto Paes³, Maria Ribeiro Lacerda ${ }^{4}$

1Enfermeira. Doutoranda em Enfermagem pelo Programa de Pós-Graduação da Universidade Federal do Paraná. Cascavel-PR-Brasil. Enfermeira. Mestre em Enfermagem. Docente da Universidade Estadual do Centro Oeste. Guarapuava-PR-Brasil.

${ }^{3}$ Enfermeira. Doutora em Enfermagem. Docente da Universidade Federal do Paraná. Curitiba-PR-Brasil.

${ }^{4}$ Enfermeira. Doutora em Filosofia. Docente da Universidade Federal do Paraná. Curitiba-PR-Brasil.

RESUMO: Pesquisa exploratória em Unidade de Terapia Intensiva adulto de um hospital de ensino de Curitiba/ Paraná, com coleta de dados de agosto a setembro de 2010. Participaram oito profissionais de enfermagem, cujos objetivos foram apreender a percepção da equipe de enfermagem sobre a violência ocorrida na unidade e reações desta equipe mediante o evento. Os dados obtidos, por entrevista em grupo e pela Análise de Conteúdo, permitiram as seguintes categorias: a violência advinda do paciente contra a equipe enfermagem; motivos de violência durante o cuidado de enfermagem e reação da equipe de enfermagem à violência provocada pelo paciente. Encontrou-se que a violência ocorre pela não resolutividade do problema do paciente, podendo vir de familiares ou de pacientes e pela falta de comunicação como antecipação do cuidado. Conclui-se que a comunicação é instrumento para o cuidado de enfermagem e pode contribuir para a não violência aos indivíduos que trabalham para promover o cuidado em saúde.

DESCRITORES: Enfermagem; Violência; Unidades de terapia intensiva.

\section{ANALYSIS OF SITUATIONS OF VIOLENT PATIENTS IN AN INTENSIVE CARE UNIT}

\begin{abstract}
This exploratory study was undertaken in an Adult Intensive Care Unit in the teaching hospital in Curitiba in the Brazilian state of Paraná, with data being collected in August and September 2010. The participants were eight nursing professionals, and the aim was to understand the nursing team's perception regarding the violence which occurred in the unit, and this team's reactions to the event. The data obtained through group interviews and Content Analysis allowed the following categories to be identified: 'The violence arising from the patient against the nursing team'; 'Reasons for violence during nursing care'; and 'The nursing team's reaction to the violence caused by the patient'. It was found that the violence occurs as a result of the patient's problem not been resolved, and may come from family members or from patients, and can result from lack of communication ahead of the care being undertaken. It is concluded that communication is an instrument for the nursing care and can contribute to non-violence for the individuals who work to promote healthcare.
\end{abstract}

DESCRIPTORS: Nursing; Violence; Intensive care units.

\section{ANÁLISIS DE SITUACIONES DE PACIENTES AGRESIVOS EN UNIDAD DE TERAPIA INTENSIVA}

RESUMEN: Investigación exploratoria en Unidad de Terapia Intensiva adulta de un hospital de enseñanza de Curitiba/ Paraná, con obtención de datos de agosto a septiembre de 2010. Participaron ocho profesionales de enfermería, cuyos objetivos fueron aprehender la percepción del equipo de enfermería sobre la violencia en la unidad y reacciones de este equipo acerca del evento. Los datos obtenidos, por entrevista en grupo y por el Análisis de Contenido, permitieron las siguientes categorías: la violencia del paciente contra el equipo de enfermería; motivos de violencia durante el cuidado de enfermería y reacción del equipo de enfermería a la violencia provocada por el paciente. Se llegó a la conclusión de que la violencia ocurre por ignorarse el problema del paciente, siendo posible ser eso de responsabilidad de familiares o de pacientes y por la falta de comunicación como antecipación del cuidado. Se constata que la comunicación es instrumento para el cuidado de enfermería y puede contribuir para la no violencia a los individuos que trabajan para promover el cuidado en salud. DESCRIPTORES: Enfermería; Violencia; Unidades de terapia intensiva. 


\section{INTRODUÇÃO}

A Unidade de Terapia Intensiva (UTI) é local para atendimento a pacientes graves ou com risco de morte, que necessitam de assistência ininterrupta. Para proporcionar o cuidado de enfermagem, o profissional que atua neste ambiente precisa conhecer os recursos disponibilizados pela unidade e se inteirar dos riscos aos quais o paciente pode ser submetido. Cabe ressaltar que o cuidado de enfermagem, mais do que o desenvolvimento de atividades junto ao paciente, atinge dimensões que extrapolam o cuidado técnico por contemplar o indivíduo em toda sua subjetividade.

No desempenho do cuidado ao paciente crítico, pode haver intercorrências que fazem com que o profissional de enfermagem seja acometido pela agressão, física ou psicológica, advinda do paciente, familiares ou mesmo por eventos adversos como a agressividade entre os próprios integrantes da equipe, motivada por estresse em decorrência do desempenho de sua prática profissional. Ultimamente, tem sido crescente o número de publicações que investiga esse fenômeno no ambiente de trabalho de enfermagem, tendo em vista os danos que causam ao indivíduo e seus reflexos diretos no desempenho de sua prática ${ }^{(1)}$.

Estudo que investigou causas decorrentes da agressividade à equipe de enfermagem, em UTIs de Florianópolis-SC-Brasil, encontrou que os participantes demonstravam alto nível de insatisfação com o ambiente de trabalho, tendo o relacionamento interpessoal sido apontado como o fator mais estressante ${ }^{(2)}$.

O estresse que envolve a equipe de enfermagem no desenvolvimento de suas atividades em UTI se dá pela característica própria que esta unidade tem, tanto pelo estado de saúde crítico do paciente quanto pela gama de procedimentos e equipamentos envolvidos. O fenômeno da violência, que acontece em toda a área da saúde, tem maior frequência quando se trata da equipe de enfermagem, isso por serem estes os profissionais que permanecem maior tempo do desempenho de sua prática, em contato com pacientes e familiares que podem - em virtude de insatisfação e descontentamento - agir de forma hostil ou mesmo violenta ${ }^{(3)}$.
Por outro lado, a equipe de enfermagem pode também se deparar com atendimento a pacientes com transtorno mental ou que apresentam tal quadro em decorrência de comorbidades clínicas. Atualmente ambos são atendidos em hospitais gerais e em algumas situações em terapia intensiva. Esses indivíduos podem, assim como qualquer outro paciente, apresentar manifestações de comportamento violento, caracterizando uma emergência. Em tal situação, será requerida abordagem específica visando ao controle ou à manutenção da segurança para o paciente e os demais em seu entorno ${ }^{(4-5)}$.

Há que se considerar que os profissionais de enfermagem, em sua maioria, atribuem ao portador de transtorno mental o status de perigoso e agressivo. Deste modo, suas primeiras atitudes são providenciar contenção física e medicação o mais rápido possível, alegando proteção para a equipe e para o paciente ${ }^{(5)}$.

Este comportamento foi observado em estudo feito com profissionais de enfermagem, de um pronto atendimento de um hospital geral, mostrando os sujeitos com receio e medo em prestar cuidados ao paciente portador de transtorno mental ${ }^{(6)}$. Assim, constata-se a manutenção do estigma historicamente construído em torno do portador de transtorno mental, de violento e possuidor da característica de periculosidade.

Considerando o complexo fenômeno da violência, presente em todos os locais do cotidiano da prática do cuidado de enfermagem, desenvolveu-se este estudo com o objetivo de apreender a percepção da equipe de enfermagem sobre a violência ocorrida em unidade de terapia intensiva e suas reações mediante o evento.

\section{MÉTODO}

Pesquisa exploratória qualitativa, com coleta de dados entre agosto e setembro de 2010, em um hospital geral de ensino de Curitiba-PR-Brasil na UTI.

Trata-se de uma unidade para tratamento de pacientes adultos, com os mais diversos acometimentos clínicos e comorbidades, entre eles o transtorno mental, constatado por anotações em prontuário. Todo indivíduo admitido nessa unidade advém do pronto atendimento da instituição. 
Foram convidados a fazer parte dessa pesquisa 20 profissionais da equipe de enfermagem, tendo participado oito: dois enfermeiros, um técnico e cinco auxiliares de enfermagem. A equipe escolhida, por solicitação do serviço, foi do turno da manhã, por ser a mais volumosa e possibilitar que alguns dos profissionais se afastassem, por um período, do cuidado para participar da pesquisa.

Os critérios de inclusão dos participantes foram: ser profissional da equipe de enfermagem alocado na UTI da instituição estudada, que se dispusesse a participar de encontros entre os participantes da pesquisa.

Foram realizados três encontros gravados, o local para realização dessa atividade foi a sala de reuniões da UTI adulto, em dias consecutivos, no turno da manhã, com duração em média de duas horas cada uma, nas quais se discutiu o tema "A violência no ambiente de trabalho da UTI".

No primeiro encontro foi apresentada a proposta, a metodologia dos encontros e coletada da assinatura no termo de consentimento livre e esclarecido. Na sequência, iniciou-se a discussão pelo tema violência com uma pergunta aberta: Qual sua vivência de violência praticada pelo paciente no seu ambiente de trabalho? Após todos terem se pronunciado, um novo questionamento foi feito: Você considera que a agressão em ambientes de saúde é passível de ocorrer por quais pessoas? Deu-se por encerrado este encontro quando todos os participantes apresentaram suas colocações sobre a temática.

No segundo encontro foram retomados os temas discutidos no encontro anterior e, na sequência, começaram as discussões com a questão: Quais os possíveis motivos para a violência sofrida pela equipe de enfermagem? Na continuidade, outra questão foi lançada ao grupo para o debate: Qual a reação da equipe de enfermagem mediante a violência recebida?

No terceiro encontro, foram projetadas transcrições de alguns tópicos dos encontros anteriores para guiar a teorização com base em literatura, sanar dúvidas elencadas pelos sujeitos durante as discussões do primeiro e segundo encontro, pois essa atividade teve por intuito caráter educativo.

Os dados coletados nos três encontros foram analisados conforme proposto pela Análise Temática(7), composta por escolha e organização do material a ser analisado, posterior categorização e teorização com base em literatura sobre a temática e objetivos propostos para este estudo.

Este artigo derivou do projeto de pesquisa aprovado pelo Comitê de Ética da Universidade Federal do Paraná, sob o registro 1017.142.10.09, CAAE: 0242.0.208.091-10. Como forma de manter o anonimato dos participantes, para sua identificação neste artigo, foi utilizada a letra "S", seguida por numeração arábica.

\section{RESULTADOS}

Os participantes dos três encontros dessa pesquisa, realizados com oito profissionais de enfermagem, eram todos do sexo feminino, com idade média de 37 anos e, dez anos e meio de média geral de prática profissional de enfermagem.

Das análises das transcrições dos encontros, obtiveram-se as seguintes categorias: A violência advinda do paciente contra a equipe enfermagem; Motivos de violência durante o cuidado de enfermagem; e Reação da equipe de enfermagem à violência provocada pelo paciente.

\section{A violência advinda do paciente contra a equipe enfermagem}

De acordo com as falas dos sujeitos, a violência que a equipe sofre advém de pacientes com sintomas e sequelas neurológicas, que acabam manifestando confusão mental e, por isso, se tornam agressivos. Houve referência ao medo pela equipe de agressão advinda de paciente com transtorno mental e que os profissionais de enfermagem não sabem lidar com esta clientela. Relataram, ainda, dificuldade em diferenciar um quadro agudo de transtorno mental de um quadro de sintomas clínicos neurológicos. Por outro lado, houve colocações de que são poucos os pacientes com transtorno mental atendidos na UTI, mas, quando isso ocorre, a equipe os percebe como mais calmos e fáceis para prestar cuidado. Alguns relatos destacam esses aspectos:

Na UTI é mais o paciente com sequelas de AVC [Acidente Vascular Cerebral], ou paciente com 
encefalopatia hepática e eles acabam agredindo mesmo. (S4)

Nós não sabemos identificar se o paciente está somente confuso ou que tipo de confusão [...] não sabemos identificar se ele está surtando ou se é do quadro neurológico, mas também não sabemos lidar com o portador de transtorno mental. (S7)

A equipe tem medo de o portador de transtorno mental agredir [...], atendemos poucos desses pacientes. Ele é o mais tranquilo [...] para nós é o paciente muito mais fácil de lidar. (S3)

\section{Motivos de violência durante o cuidado de enfermagem}

A violência sofrida de acordo com os profissionais entrevistados decorre de uma reação do paciente ou do familiar ante a abordagem feita pelo profissional; estresse pela falta de solução do seu problema; não tolerância do ambiente e paciente com dor ou por um procedimento pelo qual se sente invadido em sua privacidade. Algumas falas retratam estas situações:

A agressão ocorre sempre porque alguém não resolve um problema, eles buscam uma solução e você não tem a solução [...] o paciente não quer tomar banho [...] ou quando vai trocá-lo e ele fala que não quer. Então ele fica quieto, ou começa a chorar, ou fica mais agressivo, ele sempre tem uma reação. (S1)

[...] quando o familiar agride é porque a gente fez alguma coisa para que ele agredisse [...] falei alguma coisa que o ofendeu naquele momento em que ele estava sensível [...]. (S3)

Tínhamos um paciente esquizofrênico internado [...] e precisamos coletar um swab retal dele. Para ele, aquilo foi uma agressão. (S8)

Com relação à manifestação de comportamentos agressivos pelo paciente, os sujeitos acreditam que quando o profissional estabelece diálogo com comunicação efetiva, esta situação pode ser amenizada, uma vez que o indivíduo terá preparo antes do procedimento. Os discursos a seguir tratam deste aspecto:

A comunicação é de suma importância, nós perdemos a oportunidade de ouvir essas pessoas [...] porque ele não está entendendo o que estou fazendo [...] e eu não consigo realizaro cuidado. (S7)

[...] sem diálogo não se resolve o problema [...]. Eu acho que falta à equipe se comunicar [...] muitas vezes, eu causo a agressão sem querer porque não dialogo com o paciente. (S8)

Nas falas dos entrevistados de S7e S8 o portador de transtorno mental pode agredir como forma de defesa a uma ameaça, seja por situação real ou imaginária:

[...] acho que o medo, a invasão de privacidade, a desconfiança, a insegurança fazem os pacientes agredir. Quando é portador de transtorno mental, a equipe acha que não precisa avisar, não precisa falar e por isso o paciente acaba tendo desconfiança. O profissional chega para passar uma sonda e não avisa, é claro que vai ser agredido [...]. (S7)

Se o paciente psiquiátrico acha que tem que se defender de alguma coisa, ele vai agredir porque ele precisa resolver aquele problema, mas ele está buscando defesa. O principal ponto é isso, ninguém agride do nada [...] então agride quando sente que está em perigo. (S8)

\section{Reação da equipe de enfermagem à violência provocada pelo paciente}

Quanto à reação da equipe após um episódio de violência, alguns sujeitos pontuaram a contenção física. Para alguns há profissionais sem paciência que chegam ao trabalho trazendo uma carga excessiva de estresse, tal como relatam:

[...] às vezes o profissional está mais doente que o paciente. Então ele já vem com uma carga com um estresse tão grande. (S4)

[...] acho que para todos nós, depois de uma 
carga bem grande de sofrimento ou de desgosto, de agressões verbais, chega uma hora que acabamos agredindo alguém [...] você está tão cansado. (S3)

\section{DISCUSSÃO}

Os participantes pontuaram que não estão preparados para atender pacientes que manifestam alterações mentais, pois não sabem reconhecer a diferença entre surto psicótico e confusão mental. Também, revelam que não têm habilidades para prestar cuidados ao portador de transtorno mental. A esse respeito, a literatura aponta que o despreparo da equipe de enfermagem, na abordagem da pessoa com transtorno mental em agitação psicomotora, pode acarretar erro de compreensão do cuidado a ele dispensado. Essa situação pode levar o paciente a se sentir pressionado ou, de alguma forma, agredido e, no intuito de se defender, resultar em atos violentos contra a equipe de enfermagem ${ }^{(8-9)}$.

Destaca-se a necessidade de avaliar se a situação de violência contra profissionais de saúde pode ser evitada, haja vista que a pouca qualificação profissional, para a previsão de incidentes violentos contra a equipe, faz com que a violência ocorra, e os profissionais menos experientes são os mais atingidos por investidas do paciente violento ${ }^{(10)}$.

É relevante atentar para o fato de que o ser humano se torna agressivo quando, de certa forma, é reprimido, e o opressor impõe seu ponto de vista ao oprimido. A dominação do outro pode ocorrer entre dois indivíduos ou dois grupos, cada um exercendo a violência como forma legítima para defesa de seus interesses, expressando assim a ideia de dominação(11). Isso é confirmado nas falas dos participantes da pesquisa ao externar que o paciente se torna agressivo como forma de reação a uma ação praticada pela equipe e interpretada pelo paciente como algo agressivo, sendo, portanto, a violência a maneira que ele encontra para mostrar seu descontentamento com a situação.

Qualquer ato que transforme o indivíduo em objeto desprovido de vontade é considerado violento. Com o intuito de manter a harmonia na convivência entre seus iguais, o homem criou a ética, um meio de garantia dos direitos do sujeito como ser humano, dotado de racionalidade e livre arbítrio, não sendo passível de manipulação. A ética elenca normas, mostrando conceitos gerais do que é permitido e do que é proibido como forma de impor limites à ação humana ${ }^{(12)}$.

Quando o indivíduo interpreta o cuidado que recebe como uma ameaça para sua integridade, ele pode reagir de forma agressiva. Nessas situações, é preciso utilizar a comunicação terapêutica com o intuito de esclarecer a necessidade de tal procedimento. Contudo, ainda assim existe a possibilidade de que o paciente possa investir contra a equipe de enfermagem. Nesses casos, o enfermeiro procede com a avaliação global da situação do paciente e verifica a necessidade da contenção física como medida terapêutica. A contenção física somente será utilizada em última situação, quando não houver possibilidade de diálogo e se perceba que o indivíduo põe em risco sua integridade física ou mesmo a da equipe que o atende ${ }^{(13)}$.

No que se refere ao comportamento violento do paciente para com a equipe, há que se atentar para o fato de o bem-estar psicológico do indivíduo ficar abalado pelas dúvidas, incertezas e medo do desconhecido, de estar num lugar onde não se sinta à vontade ${ }^{(14)}$. Estes sentimentos também são compartilhados por sua família, que sofre da mesma forma que o paciente, na ânsia de um tratamento urgente para a melhora do sofrimento. Nesta situação, o enfermeiro tem papel fundamental de prestar o cuidado com uso da comunicação terapêutica personalizada, que se torna um instrumento fundamental para a prática da enfermagem, isso com vistas a atender as necessidades do paciente e familiares, esclarecendo dúvidas sobre o procedimento que o paciente receberá, respondendo às suas inquietações como forma de tranquilizá- $\operatorname{los}^{(1)}$.

Sobre a importância da comunicação entre o profissional de enfermagem e o paciente, a qualidade do diálogo extrapola a execução de técnicas e contempla um cuidado mais abrangente ${ }^{(15)}$.

A comunicação é imprescindível entre profissional e paciente por ser um processo característico dos seres humanos, promover a interação e a compreensão daquilo que um indivíduo quer comunicar aos outros e por possibilitar compartilhar angústias e inseguranças, permitindo o auxílio ao outro e a satisfação das necessidades do paciente ${ }^{(16)}$. Na relação com o 
paciente, o enfermeiro o percebe como ser que carece de cuidados e se identifica como prestador de um cuidado individualizado que venha a atender as necessidades de quem dele precisa ${ }^{(17)}$.

Essa violência advinda do paciente, seja ela em sua forma verbal ou física, pode ser interpretada pelo profissional como intencional e não em decorrência do quadro de confusão mental que o paciente apresenta. Isso gera, no profissional, insatisfação, frustração, inconformidade e, em determinadas situações, ele reage agressivamente contra o paciente, como forma de defesa ao que ele interpretou como violência recebida.

A capacitação em serviço é fundamental para que os profissionais da equipe de enfermagem reconheçam as reações agressivas do paciente - em situação de agitação psicomotora - como decorrentes da exacerbação dos sintomas neurológicos ou transtorno mental, e não direcionadas à equipe com a intenção proposital de causar dano físico ou moral. Essa compreensão é de suma importância para que o cuidado a pacientes que apresentam agressividade, decorrente de seu estado de confusão mental, possa ser desenvolvido sem agravos para a saúde desse indivíduo e sem implicações éticas para a equipe que Ihe presta cuidados.

\section{CONSIDERAÇÕES FINAIS}

A vivência da equipe de enfermagem da UTI, em relação à violência provocada pelo paciente mostrou que geralmente ela é advinda dos pacientes, entre os quais, estão os portadores de transtorno mental. Nestes casos, evidenciou-se que os relatos de violência não foram gratuitos, mas motivados pela invasão de privacidade ou mesmo pela falta de comunicação.

A falta de comunicação entre a equipe de enfermagem e o paciente, como forma de antecipação ao cuidado a ser prestado, pode fazer com que ele interprete como uma agressão e então possa agir com violência.

Em outro aspecto, a equipe de enfermagem ponderou que a violência endereçada aos profissionais, advinda do paciente, tem como fator desencadeante a falta de resolutividade para seu problema. Com relação à violência perpetrada pelos familiares, os profissionais a caracterizam como reação à forma como a equipe se dirige $\mathrm{e}$ atende esse familiar, sendo, portanto, um meio de defesa à violência recebida da equipe.

É premente a necessidade de implementação de programas de educação permanente para discutir situações de violência advinda de pacientes contra a equipe; para refletir sobre os desencadeadores desse fenômeno e para compreender que a violência não é gratuita e intencional, mas decorrente de momentos de confusão do paciente.

\section{REFERÊNCIAS}

1. Santos AMR, Soares JCN, Nogueira LF, Araújo NA, Mesquita GV, Leal CFS. Violência institucional: vivências no cotidiano da equipe de enfermagem. Rev. bras. enferm. [Internet] 2011;64(1) [acesso em 19 abr 2014]. Disponível: http://dx.doi.org/10.1590/ S0034-71672011000100013

2. Coronetti A, Nascimento ERP, Barra DCC, Martins JJ. $O$ estresse da equipe de enfermagem na unidade de terapia intensiva: o enfermeiro como mediador. Arq. Catarin. Med. [Internet] 2006;35(4) [acesso em 19 abr 2014]. Disponível: http://www.acm.org.br/revista/pdf/ artigos/394.pdf

3. Vasconcellos IRR, Abreu AMM, Maia EL. Violência ocupacional sofrida pelos profissionais de enfermagem do serviço de pronto atendimento hospitalar. Rev. Gaúcha Enferm. [Internet] 2012;33(2) [acesso em 19 abr 2014]. Disponível: http://dx.doi.org/10.1590/S198314472012000200024

4. Campello AEC, Arribas CG. Agitação psicomotora em emergência. In: Falcão LFR, Costa LHD, Amaral JLG. Emergências: fundamentos e práticas. $1^{\mathrm{a}} \mathrm{ed}$. São Paulo: Martirani; 2010. p. 1055-63.

5. Campos CJG, Teixeira MB. O atendimento do doente mental em pronto-socorro geral: sentimentos e ações dos membros da equipe de enfermagem. Rev Esc Enferm USP. [Internet] 2001;35(2) [acesso em $10 \mathrm{fev}$ 2010]. Disponível: http://dx.doi.org/10.1590/S008062342001000200008

6. Paes MR. Cuidado de enfermagem ao paciente com comorbidade clínico psiquiátrica no pronto atendimento de um hospital geral [dissertação]. Curitiba (PR): Universidade Federal do Paraná; 2009.

7. Bardin L. Análise de conteúdo. 9a ed. Lisboa: Edições; 2009.

8. Sadock BJ, Sadock VA. Compêndio de psiquiatria: ciência do comportamento e psiquiatria clínica. Trad. Cláudia Dorneles. 9a ed. Porto Alegre: Artmed; 2007. 
9. Estelmhsts P, Brusamarello T, Borille D, Maftum MA. Emergências em saúde mental: prática da equipe de enfermagem durante o período de internação. Rev. enferm. UERJ. [Internet] 2008;16(3) [acesso em 24 jun 2010]. Disponível: http://www.ebah.com.br/ emergencias-em-saude-mental-pratica-da-equipede-enfermagem-durante-o-periodo-de-internacaopdf-a74092.html

10. Antonius D, Fuchs L, Herbert F, Kwon J, Fried JL, Burton PRS, et al. Psychiatric assessment of aggressive patients: a violent attack on a resident. Am. J. Psychiatr. [Internet] 2010;167 [acesso em 22 mai 2013]. Disponível: http://ajp.psychiatryonline.org/data/ Journals/AJP/1821/appi.ajp.2009.09010063.pdf

11. Viacava JAC. Encontros de um empleado: a violência bárbara e a coerção civilizadora em José Encarnación de Zás (Uruguai, 1817 - 1851). Rev. Hist. Reg. [Internet] 2004;9(2) [acesso em 26 out 2011]. Disponível: http://www.revistas2.uepg.br/index.php/rhr/article/ viewFile/2201/1680

12. Chauí M. Convite à filosofia. $14^{a}$ ed. São Paulo: Editora Afiliada; 2012.

13. Paes MR, Borba LO, Brusamarello T, Guimarães AN, Maftum MA. Contenção física em hospital psiquiátrico e a prática da enfermagem. Rev. enferm. UERJ. [Internet]. 2009;17(4) [acesso em 14 jun 2014]. Disponível: https://www.revistas.unijui.edu.br/index. php/contextoesaude/article/viewFile/1590/1336

14. Negreiros PL, Fernandes MO, Macedo-Costa KNF, Silva GRF. Comunicação terapêutica entre enfermeiros e pacientes de uma unidade hospitalar. Rev. Eletr. Enf. [Internet] 2010; 12(1) [acesso em 25 jun 2011]. Disponível: http://www.revistas.ufg.br/index.php/fen/ article/view/9529/6598

15. Pontes AC, Leitão IMTA, Ramos IC. Comunicação terapêutica em enfermagem: instrumento essencial do cuidado. Rev. bras. enferm. [Internet] 2008;61(3) [acesso em 23 abr 2013]. Disponível: http://dx.doi. org/10.1590/S0034-71672008000300006

16. Barros LM, Araújo TM de, Neri MFS, Soares E, Caetano JA. Internação em uma unidade de emergência hospitalar: vivência. Cogitare enferm. [Internet] 2013;18(2) [acesso em 02 fev 2014]. Disponível: http://ojs.c3sl.ufpr.br/ojs/index.php/cogitare/article/ viewFile/32583/20699

17. Morais GSN, Costa SFG, Fontes WD, Carneiro AD. Comunicação como instrumento básico no cuidar humanizado em enfermagem ao paciente hospitalizado. Acta Paul. Enferm. [Internet] 2009;22(3) [acesso em 19 set 2010]. Disponível: http://dx.doi. org/10.1590/S0103-21002009000300014 